\title{
Exploration and Analysis of Teacher Training Mode Based on Network Environment
}

\author{
Xuefei Li \\ Teachers College, Jingchu University of Technology, Jingmen Hubei, 448200, China
}

Keywords: Network environment, Teacher, Training mode

\begin{abstract}
Teacher training mode exerts a direct influence on specialty growth of teacher groups. Relative to traditional training mode, teacher training under network environment has outstanding advantages. Hence, it is required to overall explore main features of teacher training mode under network environment and on the basis of comparison and analysis of traditional training mode and modern network environment training mode. Besides, this new training mode should be continuously improved. This paper analyzes the shortcomings of traditional teacher training mode and main advantages of current teacher network training mode, discusses several methods to create new teacher training modes under network environment, and proposes suggestions on improvement of new teacher training mode under network environment.
\end{abstract}

\section{Introduction}

Whether educational reform in china can achieve success depends on teachers' learning attitude and teaching behavior transformation form to a large extent. The teacher as a main force in course reform urgently needs to achieve training professionalization and normalization. Teacher training in traditional mode cannot meet objective development demand in both quantity and quality. How to better apply modern network technology to serve for teacher training has become one of important topics to improve teachers' quality in the new situation. In recent years, an increasing number of teacher trainings start to introduce network technology, and the range of training has extended to senior high school, primary school and even kindergarten teachers from college teachers. Teacher training based on network platform is widely different from traditional mode in the purpose, mode and technical means. Thus, how to better apply network environment to organize teacher network training mode has become a topic in need of in-depth discussion by professional people of teacher training.

\section{Shortcomings of traditional teacher training mode}

Firstly, training mode is not flexible enough, and the form is too single. Such training mode fails to overall apply modern education technology and network resources. Secondly, the training effect is not ideal enough. It can neither meet teachers' diversified learning and training demand nor solve specific problems well. Thirdly, traditional teacher training mode mainly adopts intensive teaching and pays attention to all-round unification of time, site and content. Teachers as adult learners have strong sense of unification in the family and work, which will certainly influence the effect of participation in traditional training and learning and naturally affects lifelong education. Fourthly, the society has high expectations for teachers' knowledge and ability, which increases extreme complexity of teacher training. Teachers should not just deeply understand the course knowledge they teach and basic teaching methods, but also hope to implement higher-level thinking method, deeply know all kinds of interdisciplinary knowledge and prove their leadership and communication ability. Traditional training mode is difficult to deal with these. Fifthly, traditional training mode mainly belongs to infusion type where the teacher serves as the subject. The teachers participating in the training can only passively receive all kinds of knowledge. In this way, teachers' subjective initiative will lower, which will affect the training effect seriously. 


\section{Main advantages of teacher network training mode}

Firstly, network convenience can well improve teacher training effectiveness and efficiency. The following network advantages should be applied: fast network information transmission speed, large amount of information, strong interactivity, real-time communication and no space and time limitation etc. Teacher training under network environment can drive teachers to update education and teaching idea, professional knowledge and teaching technology. In this way, teachers can continuously expand the approaches to acquire new knowledge, technology and method and then boost effectiveness of teacher training. Secondly, network training can improve system advantage and modern education technology. Under the same investment state, the number of training participants presents the rise of geometrical progression, and the effect of teacher training is further improved. Thirdly, network openness can facilitate teachers' learning initiative, and the huge contradiction between work and learning can be well relieved. Open training under network environment can well expand the time and space boundary. Thus, students can receive all kinds of online trainings anytime and anywhere, and the courses may be repeated. Besides, they can choose the contents they want to learn, and more rationally arrange training time. Meanwhile, such mode can give full play to effectiveness of teachers' continuous education, and improve teachers' initiative and innovation so as to really achieve interaction and research of teacher training, let teacher training and their work achieve good coordination and reduce work-learning contradiction. Fourthly, network training is quite extensive. Exchange is the starting point and ending point of learning activity, also the main driving force of all learning activities and the demand of human exchange. Network can provide teachers with a virtual community where learners and teachers can exchange synchronously and fast feed back corresponding information by various communication tools. Meanwhile, teachers can cooperate with each other and improve free learning ability. Fifthly, network training can achieve independence. In view of ever-changing learning environment, students can have quite relaxing learning situation. Network can confirm students' subject position. They can learn and consolidate the contents they cannot understand or master well in training process at will, and sustainably research the problems they are interested in. this can fully exert students' independence. Under the strong support of network technology, teachers can get rid of traditional passive learning and enter active learning stage so as to cultivate their learning initiative and improve training effect.

\section{Several methods to create new teacher training modes under network environment}

Firstly, establish a virtual community for teacher training. The virtual community for teacher training mainly refers to a virtual community which is set up for normal implementation of training activities. It not just includes network environment, but also covers all persons involved in the educational training activity. The reason why a virtual community should be set up in the teacher training process is that network can bring richer and more superior training and educational resources for the training. Meanwhile, as network era comes, network has become one of very significant components in the life of modern people, so teachers should pay much attention to and know network in order to adapt development demand under network environment. In this way, it is not enough to only provide convenient network for teachers participating in the training. It is also necessary to help them more profoundly realize the important functions of network. Hence, it is required to design special training website for the specific training content and training objects and provide more abundant training resources for teachers. Through the efficient exchange platform and favorable network service, the teachers can be overall guided to participate in the training so as to deepen cognition of network. Secondly, establish network platform for equal exchange. How to know the actual feeling of teachers participating in the training is a difficult problem. The emergence of forum offers a good method to solve this problem. Via the network forum, the teachers participating in the training can apply the form of anonymity to express their views or suggestions. In this way, they can express their ideas more truly. Therefore, the teachers responsible for training and learning should pay much attention to and intensify network forum application. They can not just learn and discuss via network forum, but also gain actual demand of students participating in the training. In addition, 
WeChat, QQ and other network instant communication tools may be applied for real-time online exchange. Of course, network forum also has a limitation, i.e. non-instantaneity. Thus, the teachers participating in the training should explore application of WeChat, QQ and other network instant communication tools so that students and teachers can discuss independently and deeply, which can further improve students' training enthusiasm and motivate their creation potential. Thirdly, let students partake in network management. The organizer in charge of teacher training should not just pay comprehensive attention to various affairs in network platform management, but also fully encourage and guide teachers to take part in network management. Hence, the organizer of teacher training should apply of teacher training to deepen their comprehension and carry out comprehensive and in-depth researches.

\section{Suggestions on improvement of new teacher training mode under network environment}

Firstly, new training mode under network environment should be explored more actively. The platform resource of teacher network training should be applied to facilitate network course setting. Besides, more teachers are required to take active part in establishing open, compatible, sharing and efficient training service mechanism so as to better satisfy students' different learning requirements. Secondly, competitive course construction should be enhanced. It is required to course construction all kinds of superior training resources, improve classroom teaching quality, let students gain ideal education and get teaching sharing in a larger scope. Thirdly, teacher training intensity should improve. Besides, it is required to create a favorable teacher lifelong training system, associate teacher training with job title promotion and overall simulate teachers for independent study. In-job research and study, school-based learning and remote training should be applied to enrich training means, enhance teacher training work, boost teachers' cognition of training and learning, and continuously improve teachers' subjective initiative so as to really achieve transformation to active learning from passive learning. Fourthly, fund guarantee system should be improved. In terns of fund input, the funds should be raised through multiple ways to ensure sufficient funds and offer corresponding funds for teacher training. On this basis, it is also required to expand cooperate with enterprises and international organizations in the region to develop multiple types of industry cooperation, accelerate training through the industry and really create a training way for self-development. Fifthly, training contents should be put into practice. Theory and practice should be combined, and practical application should be especially valued. In the training process, the new course, excellent video display and evaluation of refresher course and experimental course as well as experts' teaching contents should be practically improved. Besides, multiple types of teaching materials should be effectively integrated in experts' lectures. The training content should be connected with teaching contents so as to boost timeliness and pertinence. Sixthly, training form should be improved. It is required to better give play to the functions of remote network, and stress its pertinence, openness and instantaneity features. Seventhly, modern network platform technology should be actively introduced, and maintenance and updating speed should increase. Remote education may apply network to carry out real-time communication and exchange. After network technology is implemented, instant page view of network is very huge in holidays and festivals, so the requirement for network technology is very high. However, technical obstacles of network platform seriously affect rational implementation of training work. Thus, the organizer should actively invest in online exchange platform to solve technical problems and offer the technology of uploading the assignments to check the quality of frequency, sound and image. Eighthly, in terms of student evaluation, the principle of fairness and openness should be followed. Assignment evaluation form may be introduced for student evaluation. But if only the number of articles published and ranking are required, the teachers participating in the training will have heavy psychological burden and even cannot listen to the lecture and discuss at ease. Of course, the number of articles every day should be controlled to improve the quality of assignments. Furthermore, students should spend much more time on discussion and effectively prevent arrangement copy. Ninthly, intensive training time should be confirmed. Based on remote training in recent years, generally one-week intensive training is 
adopted. Through network learning, students can associate relevant network knowledge and the problems in actual life so as to generate an ideal effect.

\section{Conclusion}

In conclusion, teachers' continuous growth cannot be completed in one day, and it is a progressive process with long-term accumulation. Network technology serves as a means or a platform of teacher training, which is of great significance. Although in current society network education training cannot overall replace traditional teacher training mode, its great function cannot be denied. It offers contemporary teachers who regard education as their responsibility with a better learning opportunity. Moreover, teachers may learn anytime and anywhere via network. In such new situation, modern network training should be combined with traditional teacher training to facilitate improvement of training quality through exerting their respective advantages.

\section{References}

[1] Lan Peian, Teacher Specialty Development and Remote Network Training: Remote Network Training Theory and Practice of Further Education of Primary and Middle School Teachers. Guangzhou: Ji'nan University Press, 2009.

[2] Mou Ya, Teachers’ Educational Technology Ability Training Based on Mixed Training Mode Case Study of Educational Technology Ability Training of Backbone Teachers in Sichuan. Software Guide (Educational Technology), 2009 (9).

[3] Li Zhengchao, Exploration of Network-based Educational Technology Ability Training Mode for Primary and Middle School Teachers. China Education Info, 2010 (2).

[4] Zhou Xiaozhang, Educational Technology Ability Training for Primary and Middle School Teachers: Practice Based on Network Learning Community. Modern Educational Technology, 2010 (6).

[5] Zhou Sumei, Innovation Experience of Educational Technology Ability Training under Network Environment. Journal of Beijing Institute of Education (Natural Science Edition), 2011 (3).

[6] Tang Jihong, Zhang Xiuqi, Cheng Lin, Evaluation of Teachers' Educational Technology Ability Training Based on BP Neural Network. Computer Technology and Development, 2013 (6). 